\title{
Algunas calas en el proceso redaccional de Un pobre hombre rico o El sentimiento cómico de la vida: del autógrafo unamuniano a la príncipe
}

\author{
MARTA FABbri \\ Università degli Studi di Ferrara
}

Título: Algunas calas en el proceso redaccional de Un pobre hombre rico o El sentimiento cómico de la vida: del autógrafo unamuniano a la príncipe.

Resumen: El artículo reconstruye las últimas fases de elaboración y los problemas ecdóticos de Un pobre hombre rico o El sentimiento cómico de la vida, la última novela $-\mathrm{y}$ entre las menos conocidas- de Unamuno. El examen de las fuentes principales (autógrafo y príncipe de 1933) y el estudio del idiolecto del autor nos permiten distinguir, dentro del texto impreso, las variantes unamunianas -introducidas en la última fase de revisión- de las innovaciones del tipógrafo.

Palabras clave: Filología, Unamuno, Un pobre hombre rico o El sentimiento cómico de la vida, variantes de autor, variantes de copia.

Fecha de recepción: 25/6/2021.

Fecha de aceptación: 4/7/2021.
Title: Some Insights into the Compositional Process of Un pobre hombre rico o El sentimiento cómico de la vida: from the Unamunian Autograph to the editio princeps.

Abstract: The article aims to analyse the last compositional phases and the difficulties raised by the philological edition of Un pobre hombre rico o $E l$ sentimiento cómico de la vida, Unamuno's last -and perhaps one of the least known- novel. The study of the principal sources (the autograph and the editio princeps of 1933) and of the author's idiolect allow to distinguish, in the printed version, the author's variants -introduced in the last phase of revision-from the typographical ones.

Key words: Philology, Unamuno, Un pobre hombre rico o El sentimiento cómico de la vida, author's variants, variants of copy.

Date of Receipt: 25/6/2021.

Date of Approval: 4/7/2021.

\section{UN POBRE HOMBRE RICO: GESTACIÓN Y PUBLICACIÓN}

Dentro del vasto y polifacético corpus unamuniano, las novelas siempre han despertado un interés especial entre la crítica, al considerarse - con contadas excepciones - como sus textos más innovadores. Sin embargo, 
algunas no tuvieron mucho éxito, verbigracia Un pobre hombre rico o $\mathrm{El}$ sentimiento cómico de la vida. Pocos son los datos sobre la escritura de esta novelita, ya que el rector de Salamanca no la refiere en su epistolario: solo disponemos de una somera descripción de su proceso creativo, trazada por el mismo autor en el prólogo al volumen San Manuel Bueno, mártir y tres historias más ${ }^{1}$. Pero en la Casa-Museo Unamuno de Salamanca (sign. caja 63/2) se custodia el autógrafo de este libro — presuntamente la copia en limpio enviada a la tipografía-, donde aparecen las fechas de conclusión de las distintas novelas, ofreciéndonos unas coordenadas temporales más precisas. Concretamente, se desprende de ellas que Un pobre hombre rico se terminó en diciembre de 1930. Por aquellos días, Unamuno, tras su regreso del destierro, acababa de componer también San Manuel Bueno, mártir y La novela de Don Sandalio jugador de ajedrez ${ }^{2}$. Su intención original era la de publicar dichas novelas en alguna revista; no obstante, solo San Manuel Bueno, mártir vio la luz de este modo, mientras que las otras dos quedaron inéditas hasta 1933: se incluyeron entonces en el volumen citado, San Manuel Bueno, mártir y tres historias más (Espasa-Calpe $)^{3}$. En principio, la colección tendría que recoger únicamente los tres textos de 1930; pero al final Unamuno agre-

1 Miguel de Unamuno, San Manuel Bueno, mártir y tres historias más, Madrid, Espasa-Calpe, 1933.

2 El autógrafo presenta las dataciones de noviembre 1930 para San Manuel Bueno, mártir y de diciembre 1930 para La novela de Don Sandalio y Un pobre hombre rico. En el prólogo del volumen de 1933, Unamuno declara que empezó a escribir tras encontrar la inspiración en San Martín de Castañeda en junio 1930; podemos inferir, pues, que la composición de las tres novelas de 1930 fue bastante rápida y que, en su conjunto, no tardó más de seis meses.

3 "Y ahora recojo aquí tres nuevas novelas bajo el título de la primera de ellas, ya publicada en La Novela de Hoy, número 461 y último de la publicación, correspondiente al día 13 de marzo de 1931 —estos detalles los doy para la insaciable casta de los bibliógrafos-, y que se titulaba: San Manuel Bueno, mártir. En cuanto a las otras dos: La novela de Don Sandalio, jugador de ajedrez, y Un pobre hombre rico o el sentimiento cómico de la vida, aunque destinadas en mi intención primero para publicaciones periódicas —lo que es económicamente más provechoso para el autor-, las he ido guardando en espera de turno, y al fin me decido a publicarlas aquí sacándolas de la inedición. Aparecen, pues, estas bajo el patronato de la primera, que ha obtenido ya cierto éxito" (Unamuno, op. cit., pp. 7-8). 
gó también Una historia de amor, un viejo cuento de 1911, que había publicado en El Cuento Semanal ${ }^{4}$.

\section{DesCripCión DEl MANUSCRITO}

La recensio de Un pobre hombre rico no es muy complicada, puesto que solo existen dos testimonios: la príncipe y el autógrafo ${ }^{5}$. El manuscrito de la Casa-Museo Unamuno comprende los autógrafos del prólogo y de las novelas de 1930 - que juntos constituyen una libreta única-y un apógrafo de Una historia de amor. Está formado por 164 cuartillas con una doble numeración ${ }^{6}$ : en el ángulo superior derecho, la que se atribuye al mismo autor - y al copista, en el caso del apógrafo-; en el ángulo superior izquierdo, la paginación moderna del archivo con lápiz (desde 1 hasta 164). Un pobre hombre rico ocupa las cuartillas con numeración moderna de 83 a 97 y es la única novela escrita tanto en el recto como en el verso de los folios. Cabe fijarse en este testimonio porque su configuración nos brinda unas informaciones de suma importancia a la hora de formular conjeturas sobre las distintas etapas de escritura de la obra. En efecto, a lo largo del autógrafo se asiste a un cambio de tinta, que parece revelar también una falta de correspondencia temporal entre diversos fragmentos de texto. Unamuno empieza a escribir con tinta azul, y a partir de la mitad de la cuartilla 85 prosigue

4 Tras la recuperación de un familiar de Una historia de amor en el archivo de las publicaciones periódicas unamunianas — donde había quedado olvidada durante más de veinte años-, Unamuno decide incluirla en su antología. Por esta razón, en marzo de 1933 el autor añade unas páginas dedicadas a la novelita en el prólogo que había cerrado en 1932. Don Miguel reflexiona y ofrece unos detalles acerca del nombre de la protagonista, pero confiesa que no se acuerda bien de la historia porque, admite sin vergüenza, no la ha releído ni revisado antes de volver a publicarla.

5 En el Fondo Miguel de Unamuno (FMU) se ha localizado, además, una copia póstuma de la novela en edición periódica bajo el título de "El sentimiento cómico de la vida”, publicada en 1952. Dicha versión muestra alteraciones supuestamente atribuibles a la censura franquista y, por esta razón, no se ha tenido en cuenta a la hora de realizar la edición filológica del texto. Dejamos para otra ocasión el análisis de esta copia, a fin de investigar más en general la incidencia de la censura en las obras unamunianas.

6 Cada texto que integra el manuscrito presenta una foliación autónoma. 
con tinta negra. El título puesto en negro contrasta, pues, con el comienzo de la obra escrito en azul y, por tanto, parece derivar de una fase posterior — quizás final— de redacción. Además, el proceso de relectura y revisión de la novela está testimoniado por la presencia de unas 'notas numéricas' insertadas en distintas partes del texto, de las que el autor se sirvió — conforme acostumbraba - para añadir, en las páginas finales (a partir de la 95) nuevos párrafos (más o menos largos) y ampliar así lo escrito en precedencia.

\section{El USUS SCRIBENDI UNAMUNIANO}

El estudio del manuscrito y, más en general, el cotejo de las dos fuentes principales - autógrafo y príncipe - nos permite reconstruir el sistema de corrección unamuniano aplicado en las últimas fases de redacción y también destacar algunas intervenciones imputables al cajista. Pero, antes de adentrarse en dicha cuestión, resultan imprescindibles unas calas previas en el idiolecto unamuniano; elemento a menudo relegado a un papel marginal, pese a que se antoje, en muchas ocasiones, la única clave para aclarar una variante de dudosa paternidad. Considerando el idiolecto del que fue rector de Salamanca, podemos detectar al menos dos aspectos distintivos: la oscilación entre las grafías $g$ y $j$ para la fricativa velar sorda $[\chi]$ y el empleo del pronombre complemento indirecto le/s en lugar del complemento directo femenino la/s (es decir, el leísmo del acusativo femenino).

Por lo que afecta a la realización del sonido fricativo velar sordo, aunque en toda la obra unamuniana las dos variantes gráficas se alternen de manera bastante casual, en Un pobre hombre rico predomina el uso antiacademicista de la $j \mathrm{y}$, concretamente, manuscrito y príncipe concuerdan en las lecciones “coger” y "recojía”, escritas con $j$ :

Rosita le recojía los sábados la ropa sucia, salvo alguna prenda que alguna vez él hurtaba para llevársela a la lavandera. Ms V]

- Hombre, no, eso de la laña es una grosería. Pero figúrate tú cojer un ánfora... Ms V $]^{7}$

7 Para citar los fragmentos del manuscrito se utilizará la sigla Ms, remitiendo a las cuartillas numeradas por el autor (con la abreviación c./cc.); mientras que la príncipe se indicará con $\mathbf{V}$. 
Respecto al segundo fenómeno, en el manuscrito figuran un par de ejemplos de leismo del acusativo femenino, rasgo dialectal típico del español hablado en el País Vasco: "le habría olido a prójima" en lugar de "la habría olido a prójima", y "le dejó el novio" en lugar de "la dejó el novio"8.

—Q Qué ha de tenerlo, madre, qué ha de tenerlo! ¿Líos él? Lo habría yo olido...

-Y si la prójima no se perfuma...

— Le habría olido a prójima sin perfumar... Ms V]

"Vaya —se decía—, a ésta ya le dejó el novio... o lo que sea... ya va sola, pero pronto vendrá otro... Ms V]

Estas anomalías pronominales se trasladaron inalteradas a la príncipe. En cambio, la edición de 1933 corrigió otro caso de leísmo del acusativo femenino registrado en el autógrafo y referido a Rosita, la protagonista:

Un día de Difuntos la llevó a ver el Tenorio. V] Un día de Difuntos

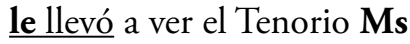

En definitiva, Un pobre hombre rico demuestra a las claras que, en los años Treinta, la lengua unamuniana conservaba algunas huellas del sustrato dialectal bilbaíno.

Otro asunto de un cierto relieve atañe a la faceta léxica; en particular, cabe dedicar unas líneas a la palabra bisteque, forma derivada del estándar bistec:

- $\mathrm{Al}$ revés, son los huéspedes los que se me antojan dedos. Y luego ese Martínez, el opositor de turno, que se la come con los ojos mientras masculla el bisteque, $\mathrm{y}$ a quien parece que le tiene como sustituto por si yo le fallo. Ms V]

8 "Aún menos difundido está el leísmo femenino ya que abarca el País Vasco, Navarra, parte de La Rioja y de Santander y las comarcas burgalesas del Valle del Ebro" (María Jesús Korkostegi Aranguren, Pío Baroja y la gramática. Estudio específico del leísmo, laísmo y loísmo y la duplicación de objetos, San Sebastián, Universidad de Deusto, 1992, p. 108). Véase también Paolo Tanganelli, "Los borradores unamunianos (algunas instrucciones para el uso)", en Crítica genética y edición de manuscritos hispánicos contemporáneos. Aportaciones a una poética de transición entre estados, coords. Bénédicte Vauthier y Jimena Gamba Corradine, Salamanca, Universidad de Salamanca, pp. 73-96 (pp. 81-83). 
Dicho término, originario de Venezuela y Honduras, tiene poco uso en España y figura en unas ediciones de los diccionarios académicos a partir de 1927 como sinónimo de "bistec" 9 . En particular, el Diccionario histórico (1936) documenta el empleo de este vocablo en Morriña (1889) de Emilia Pardo Bazán ${ }^{10}$. La escritora gallega transcurrió varios años de su vida en Madrid, igual que don Miguel, que estudió en la Universidad Central (1880-1883). Asimismo, no es su única presencia dentro del corpus unamuniano, ya que documenta su empleo también Niebla ${ }^{11}$. Además, conforme registra el CORDE, dicho lema asimismo aparece en El Practicón, tratado de cocina de Ángel Muro, publicado en 1894. Muro explica con lujo de detalles qué es el "biftec" de proveniencia inglesa y se revela interesante esta aclaración: "Las cocineras españolas a esta carne la llaman bisté y la chulería madrileña bisteque"12. Evidentemente, esta palabra representa un curioso vestigio lingüístico de la etapa madrileña de Unamuno, cuya lengua seguiría evolucionando de forma evidente sobre todo a raíz de su llegada a la ciudad del Tormes (1891), siendo bien documentada la abundante presencia de salmantinismos en su escritura ${ }^{13}$.

9 En el Diccionario Academia Manual (1989) aparece la definición: "bisteque: m. Hond. y Venez. bistec".

10 En el Diccionario Academia Histórico (1936) aparece la definición "bisteque: m. Bistec. «Si no llega pronto el bisteque, se producirán repugnantes escenas de canibalismo» Pardo Bazán, Obr., t. 7, p. 197”.

11 Miguel de Unamuno, Niebla, Madrid, Castalia, 1995, pp. 91 y 270.

12 Ángel Muro, El Practicón. Tratado completo de cocina, Madrid, Ediciones Poniente, 1982.

13 "Miguel de Unamuno llega a tierras castellanas el 2 de octubre de 1891 para ocupar la cátedra de Griego de la Universidad de Salamanca, será a partir de entonces cuando se inicie una estrecha vinculación del escritor con Castilla y, con ella, lo que Luciano González Egido ha denominado la "castellanización de su espíritu»" (María Montserrat Muriano Rodríguez, "El «Vocabulario» salmantino de Vida de don Quijote y Sancho", en Rumbos del hispanismo en el umbral del Cincuentenario de la AIH, eds. Patrizia Botta et al., 2012, VIII, pp. 260-269 (p. 260). Véase también María Montserrat Muriano Rodríguez, Roma, Bagatto Libri, "El salmantinismo léxico en Miguel de Unamuno", en El diccionario como puente entre las lenguas y culturas del mundo. Actas del II Congreso Internacional de Lexicografía Hispánica, coords. Dolores Azorín Fernández et al., Alicante: Biblioteca Virtual Miguel de Cervantes, 2008, pp. 553-560. 


\section{LAS VARIANTES DE MS}

El estudio del manuscrito desvela distintas fases de redacción de la novela. Las variantes genéticas de Ms abarcan varios tipos de correcciones —-supresiones, sustituciones y ańadidos_- que, a su vez, deberán interpretarse, en ocasiones, como retoques inmediatos de la primera fase de redacción, y, en otras, como resultados de una sucesiva revisión del autor ${ }^{14}$. Como es obvio, la dificultad reside concretamente en la identificación de la diferente naturaleza de las variantes y de su colocación, por así decir, 'temporal'. A este propósito, el estudio del manuscrito — sobre todo si autógrafo - resulta forzoso, porque brinda indicios gráficos — como el ya mencionado color de la tinta — capaces de solucionar ambigüedades.

El análisis pormenorizado del autógrafo evidencia que la mayoría de las variantes genéticas son inmediatas y, concretamente, son sustituciones, que suelen tener el fin — a menudo puramente estilístico- de cambiar o añadir pequeños matices de significado. Un ejemplo podría ser el sintagma "enamorado quedó", en que el autor tacha "enamorado" y lo sustituye por "prendado":

¡Ahora era cuando comprendió cuán hondamente •enamorado queddó» prendado quedó de ella, ahora era cuando en la oscuridad del lecho le perseguía aquel pestańeo llamativo! [Ms, c. 5] ${ }^{15}$

Las variantes presuntamente tardías son muy pocas. Podría dudarse de la cronología de este pequeño retoque, donde el pronombre reflexivo se añade debajo del renglón de escritura:

14 Se remite a Paola Italia y Giulia Raboni, Che cosè la filologia d'autore, Roma, Carocci, 2010, pp. 54-56.

15 Para la transcripción de los fragmentos del manuscrito nos serviremos de los siguientes signos diacríticos:

${ }^{i}>\mathbf{x x x x x}<$
$>\operatorname{xxxxx}<$
${ }^{i}[\mathrm{xxxxx}]$
$[\mathrm{xxxxx}]$
-lección1 1 lección2
alección1 blección2
(XXXXX)

Supresión inmediata

Supresión posiblemente tardia

Añadido inmediato

Añadido presuntamente tardio

Sustitución inmediata

Sustitución presuntamente tardia

Integración editorial 
- Lo que a usted le conviene, señor Alfonso, para curarse de esas distracciones es... ¡ casarse! $^{a}$ Case ${ }^{b}$ Cásese usted, señor Alfonso, cásese usted. Nos dan mejor rendimiento los casados. [Ms, c. 10]

Más claro es lo que sucede en la frase "esos conceptos me hacen cosquillas en el bulbo raquídeo", en la cual se nota una tachadura de "hacen cosquillas" y su sustitución por "hurgan", interlineado con tinta azul en el pequeño espacio vacío. También en este caso la corrección no figura en el mismo renglón y, además, el cambio de tinta es otra señal que corrobora la clasificación de la variante como tardía. En el mismo fragmento del manuscrito se nota también un trazo sutil con lápiz, repasado con pluma negra, que pone de manifiesto un pasaje intermedio (y anterior a la revisión efectuada sucesivamente con tinta azul) en la elaboración de dicha porción de texto [Lámina 1]:

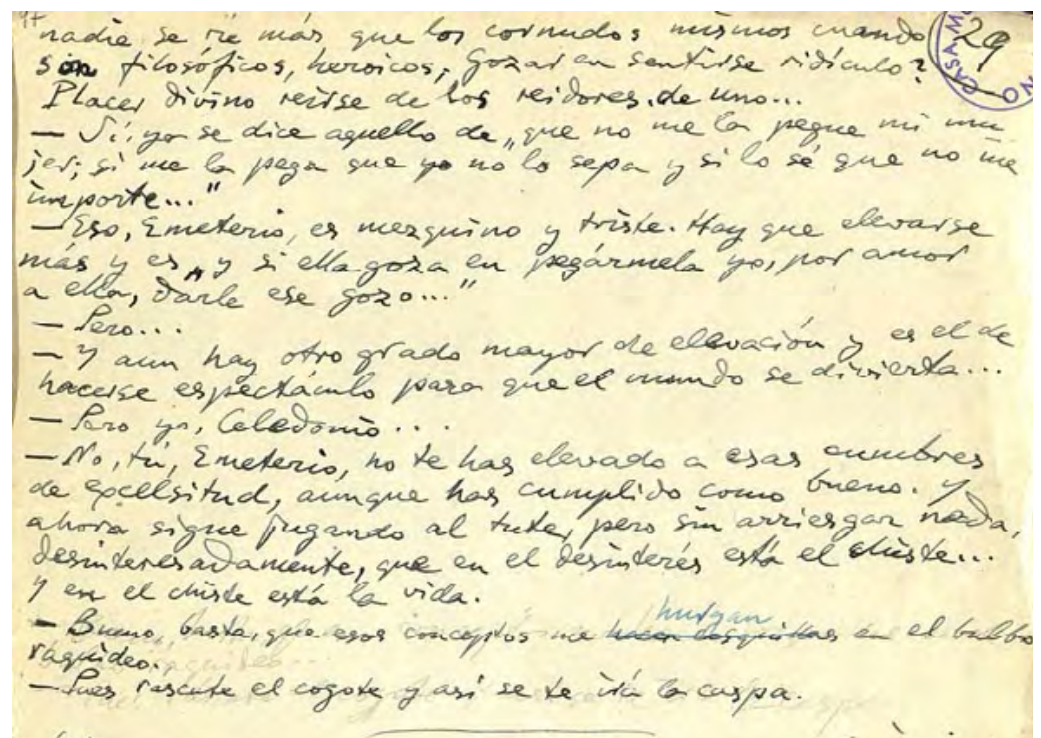

1. Fuente: Casa-Museo Unamuno, Universidad de Salamanca.

-Bueno, basta, que esos conceptos me ${ }^{a}$ hacen cosquillas ${ }^{b}$ hurgan en el bulbo raquídeo. [Ms, c. 29]

Otra cuestión sugestiva concierne a la palabra "subcociente", escrita a sabiendas de forma equivocada para que al lector le resulte evidente que 
el protagonista desconoce el significado de dicho concepto filosófico. En una segunda fase Unamuno baraja la posibilidad de insertar "(sic)", pero luego renuncia a este añadido, al no considerar necesario subrayar que se trata de la transcripción fiel de un error:

-Sí, lo que Martínez, su padre, llamaría el subconsciente...

-Pues sí, el a subcociente ${ }^{\mathrm{b}}$ subcociente (sic) 'subcociente ese...

- Subconsciente se dice... [Ms, c. 13]

Además, Unamuno añade un fragmento con el que introduce nuevos detalles narrativos, y, unas líneas más abajo, inserta un "que" para corregir un lapsus calami. Es interesante fijarse paralelamente en estas dos intervenciones porque comparten las mismas características gráficas —es decir, ambas se han trazado con lápiz en un espacio vacío al final de la cuartilla- y, en consecuencia, parecen pertenecer al mismo estadio de revisión. [Lámina 2]

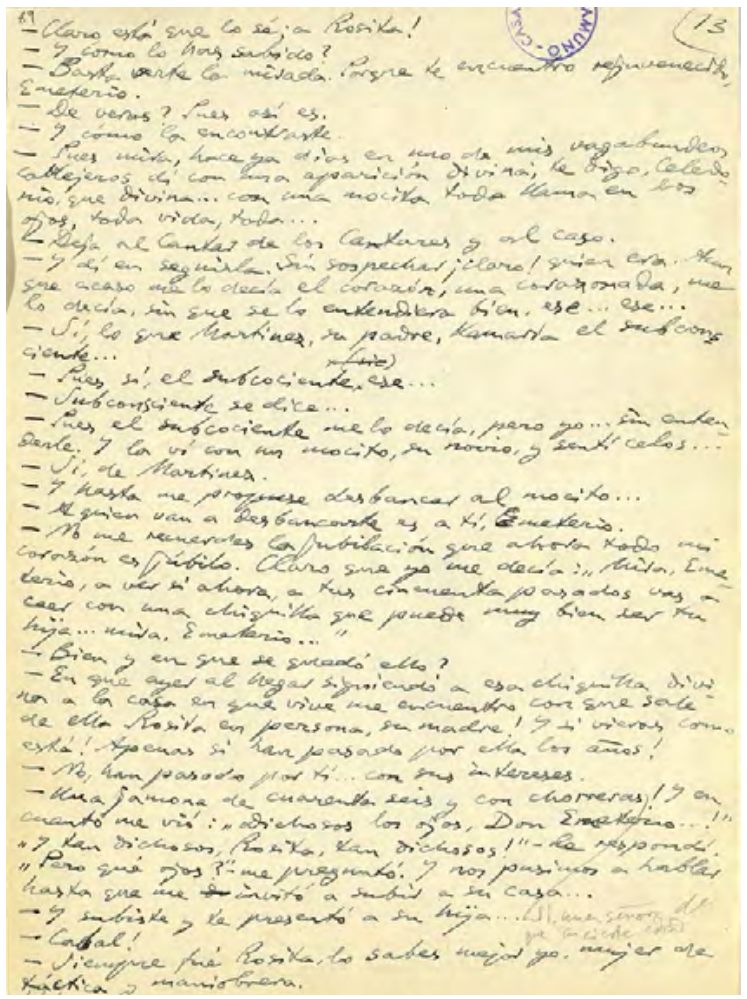

2. Fuente: Casa-Museo Unamuno, Universidad de Salamanca. 
— ¿Una jamona de cuarenta y seis y con chorreras! [Sí, una seńora de incierta edad...] Y en cuanto me vio: "¡Dichosos los ojos, Don Emeterio...!” “ ¡Y tan dichosos, Rosita, tan dichosos!”-le respondí-. “¿Pero qué ojos?” — me preguntó—. Y nos pusimos a hablar, hasta que me invitó a subir a su casa...

-Y subiste y te presentó a su hija...

- iCabal!

- Siempre fue Rosita, lo sabes mejor [que] yo, mujer de táctica y maniobrera. [Ms, c. 13]

También figura un caso curioso de supresión: en el autógrafo Unamuno elimina el "Don" delante del nombre "Emeterio", pero luego dicho tratamiento de respeto se reintroduce en la versión impresa. La variante es mínima, ya que la supresión no incide en el significado de la oración. Sin embargo, analizando el empleo de la expresión completa "Don Emeterio" a lo largo del texto, se nota que es propia solo de los diálogos y que el narrador no la utiliza. La tachadura tiene toda la pinta de ser la corrección de un lapsus calami y, por consiguiente, deberíamos interpretar la restauración del apelativo en el texto impreso como un error del cajista, que no reconoció o no entendió la tachadura:

—Demasiado, hija.

Y volvió, ¡claro está!, > Don< Emeterio a casa de Rosita.

-Mire, Don Emeterio, mi hija no quiere oír hablar de usted...

[Ms, c. 16]

Y volvió, ¡claro está!, >Don< Emeterio Ms] Y volvió, ¡claro está!, Don Emeterio V

\section{LAS VARIANTES DE V}

El texto publicado por Espasa-Calpe presenta numerosas variantes respecto al autógrafo, las cuales consisten principalmente en correcciones de lapsus calami ${ }^{16}$. Por lo general, las enmiendas atańen a cuestiones

16 “...l'autografia non garantisce la corrispondenza all' «originale $=$ testo interiore 
morfosintácticas o de concordancia en verbos o sustantivos de escaso interés.

Lo que sí resulta peliagudo es establecer la mano que se esconde detrás de dichas lecciones: ¡el autor o el tipógrafo? En muchos casos no es posible determinar si son fruto de la revisión unamuniana o se originaron en la misma imprenta, durante la composición tipográfica. Pero hay excepciones: de vez en cuando es posible atribuir la responsabilidad de la variante al tipógrafo, por la presencia de claros indicios de deslices involuntarios que pertenecen a la típica fenomenología de la copia. Un ejemplo es la omisión de "-Y ahora ya no te aburres... / — También es verdad...", que se halla en un diálogo con muchas repeticiones del sintagma "es verdad": aquí el cajista cometió un saut du même au même.

—Es verdad..., es verdad... / - Y ahora ya no te aburres... / - También es verdad... / - Y es que el solitario, el aburrido, da en hacer solitarios, ¿me entiendes?, y esto acaba por imbecilizar. Y el remedio es hacer solitarios en compañía...

—Es verdad..., es verdad... / —Y ahora ya no te aburres... / —También es verdad... / —Y es que el solitario... Ms] —Es verdad..., es verdad... / -Y es que el solitario... $\mathbf{V}^{17}$

Otro error de composición es la sustitución del adjetivo “ordenada” por "organizada": "la república bien ordenada". Este fragmento encierra una alusión indirecta del capítulo XXII (parte I) del Quijote, que Unamuno había mencionado ya en una conversación anterior entre Emeterio y Celedonio. Seguramente en este caso el compositor, al no ver las comillas,

dell'autore" a causa della possibile presenza in ogni autografo di segmenti involontariamente non corrispondenti al testo interiore, che l'autore avrebbe senz'altro corretto se avesse esaminato il suo scritto con maggiore attenzione (errori pertanto da distinguere accuratamente da quelli 'oggettivi' dovuti ad ignoranza o incapacità dell' autore, e che quindi sono autentici, corrispondendo alla sua intenzione)" (Elio Montanari, La critica del testo secondo Paul Maas, Firenze, Sismel, 2003, p. 14).

17 En los ejemplos se transcribirán la versión impresa $\mathbf{V}$ y los fragmentos correspondientes del manuscrito Ms con el auxilio de los signos diacríticos seńalados en la n. 14. El subrayado indica lo eliminado en la príncipe. 
no se dio cuenta de la cita y confundió “ordenada” con un término gráficamente parecido y facilior: "organizada".

- Y el nietastrito se debe a ti, a tu generosidad, porque tú eres el que casaste a Paquito y Clotilde. ¿Te acuerdas cuando hablábamos de tu vocación para el oficio necesarísimo en la república bien ordenada?...

en la república bien ordenada $\mathbf{M s}$ ] en la república bien organizada $\mathbf{V}$

Otra extraña sustitución consiste en el cambio de "mozas" por "masas" en la frase "la vida anterior de las mozas". Los dos términos, semánticamente distintos, se asemejan mucho a nivel fonético y gráfico. En este contexto todo hace pensar en un error derivado de una lectura equivocada. Además, fijándose en el contexto en que se encuentra la variante, se nota la presencia del término "muchedumbre", de sentido equivalente a "masas". En otras palabras, "masas" se podría interpretar como un error por atracción.

Y dio en corretear las calles, en bañarse en muchedumbre suelta, en ir imaginándose la vida interior de las mozas con quienes cruzaba, en desnudarles no solo el cuerpo, sino el alma con la mirada. la vida interior de las mozas $\mathbf{M s}$ ] la vida interior de las masas $\mathbf{V}$

Finalmente, la príncipe presenta una corruptela manifiesta que se puede subsanar fácilmente gracias a la restauración de la lección del manuscrito. En el autógrafo se lee un típico juramento: "por ahí te pudras", pero en el volumen se omitió la sílaba inicial del verbo: "por ahí te dras":

—Pues, mira, sí, me tira esto, no puedo negártelo. Sufro cuando veo que algún mocito deja a su mocita por otra, y cuando estas tienen que cambiar de mozo y cuando una que lo merece no encuentra quien le diga: ¡Por ahí te spùdras!, y aunque se ponga papel no le llega inquilino.

¡Por ahí te pudras! Ms] por ahí te dras $\mathbf{V}$

Además de dichos errores de composición del cajista o de sus pequeñas correcciones ope ingenii, hay al menos una variante del texto impreso que 
podría atribuirse al autor. Concretamente, se trata de la sustitución de "quiera" por "guste", que parece reflejar el somero labor limae de Unamuno.

- No puedo olvidar, Don Hilarión, que fue usted íntimo amigo de mi padre y que a usted más que a nadie debo este empleíllo que me permite ahorrar los intereses de lo que me dejó aquél; usted, pues, tiene derecho a preguntarme lo que guste...

tiene derecho a preguntarme lo que guste... V] tiene derecho a preguntarme lo que quiera... Ms

Como se desprende de estas calas, el cotejo entre el manuscrito y la príncipe nos faculta para reconstruir las últimas fases de composición de $U n$ pobre hombre rico, para aquilatar nuestro conocimiento del usus scribendi unamuniano y, sobre todo, para subsanar las corruptelas que, desde su primera impresión, deturparon esta novela. 